\title{
Evaluating indoor exposure modeling alternatives for LCA: A case study in the vehicle repair industry
}

\author{
Evangelia Demou $^{1 *}$, Stefanie Hellweg ${ }^{1}$, Michael P. Wilson ${ }^{2}$, \\ S. Katharine Hammond ${ }^{3}$, and Thomas E. McKone ${ }^{3,4}$
}

1. Institute of Environmental Engineering

ETH Zurich, CH-8093 Zürich, Switzerland.

2. Center for Occupational and Environmental Health

School of Public Health

University of California

Berkeley, CA, 94720, USA

3. School of Public Health

University of California

Berkeley, CA, 94720, USA

4. University of California

Lawrence Berkeley National Laboratory

One Cyclotron Road, 90R3058

Berkeley CA, 94720, USA

May 2009

This work was supported in part by the US EPA National Exposure Research Laboratory through Interagency Agreement No. DW-988-38190-01-0, with the Lawrence Berkeley National Laboratory operated for the US Department of Energy (DOE) under Contract Grant No. DE-AC02-05CH11231 and by Cooperative Agreement Number U19/EH000097-02 from the US Centers for Disease Control and Prevention (CDC). 
Evaluating indoor exposure modeling alternatives for LCA: A case study in the vehicle repair industry

Evangelia Demou ${ }^{1 *}$, Stefanie Hellweg ${ }^{1}$, Michael P. Wilson ${ }^{2}$, S. Katharine Hammond ${ }^{3}$, and Thomas E. McKone $e^{3,4}$

${ }^{1}$ Institute of Environmental Engineering, ETH Zurich, CH-8093 Zürich, Switzerland.

${ }^{2}$ Center for Occupational and Environmental Health, School of Public Health, University of California, Berkeley, CA, 94720, USA

${ }^{3}$ School of Public Health, University of California, Berkeley, CA, 94720, USA

${ }^{3,4}$ University of California Lawrence Berkeley National Laboratory, One Cyclotron Road, 90R3058, Berkeley CA, 94720, USA

\title{
RECEIVED DATE
}

*Corresponding author: Evangelia demou

Tel: +41-44-6323172; Fax: +41-44-6331061,

E-mail: evangelia.demou@ifu.baug.ethz.ch

\begin{abstract}
We evaluated three exposure models with data obtained from measurements among workers who use "aerosol" solvent products in the vehicle repair industry and with field experiments using these products to simulate the same exposure conditions. The three exposure models were the: 1) homogeneously-mixed-one-box model, 2) multi-zone model, and 3) eddy-diffusion model. Temporally differentiated real-time breathing zone
\end{abstract}


volatile organic compound (VOC) concentration measurements, integrated far-field area samples, and simulated experiments were used in estimating parameters, such as emission rates, diffusivity, and near-field dimensions. We assessed differences in model input requirements and their efficacy for predictive modeling. The One-box model was not able to resemble the temporal profile of exposure concentrations, but it performed well concerning time-weighted exposure over extended time periods. However, this model required an adjustment for spatial concentration gradients. Multi-zone models and diffusion-models may solve this problem. However, we found that the reliable use of both these models requires extensive field data to appropriately define pivotal parameters such as diffusivity or near-field dimensions. We conclude that it is difficult to apply these models for predicting VOC exposures in the workplace. However, for comparative exposure scenarios in life-cycle assessment they may be useful.

KEYWORDS. Exposure model, VOC, life cycle assessment

BRIEFS. Modeling alternatives for occupational exposure are evaluated for their standard use life cycle assessment (LCA).

\section{INTRODUCTION}

For many hazardous chemicals, concentrations and exposures in indoor environments are consistently and significantly higher than in ambient outdoor environments [1]. Consequently, inhalation intake fractions of indoor emissions can exceed those of outdoor emissions by several orders of magnitude [1-3]. For example, in vehicle repair shops, solvents in "aerosol" cans are used in large quantities during tasks such as engine 
repair, brake cleaning, oil changes, etc $[4,5]$. This produces exposure to volatile organic compounds (VOCs) among repair technicians, who typically are not protected with engineering controls or personal protective equipment [5].

Models are helpful for characterizing chemical exposures in the workplace, and are usually applied for interpreting exposure measurements and predicting indoor concentrations. Bulk-mixing models have been applied in occupational hygiene and risk assessment [6-11]. In cases of incomplete mixing conditions, multi-zone models [7, 8, 12, 13], diffusion based models $[7,14]$ or mixing factors applied to the ventilation rate have been used $[15,16]$. A problem, however, in using any of these relatively simple models is the scarcity of model performance evaluations that provide insight on their capabilities and limitations. There is a pivotal need for model calibration and evaluation based on actual exposure measurements for specific, well-characterized activities and environments.

In addition to their use in occupational hygiene, exposure models may also be applied in environmental assessments, such as Risk Assessment (RA) and Life-Cycle Assessment (LCA). Health effects from indoor exposures are often neglected in LCA. This shortcoming could lead to product or process optimizations occuring at the expense of workers or consumer health.

Work to address the assessment of indoor occupational exposure in LCA has been initiated by an international expert group working on the integration of indoor and outdoor exposure in LCA, within the UNEP/SETAC Life Cycle Initiative (http://lcinitiative.unep.fr). Hellweg et al. (2008) provided a qualitative assessment of model alternatives and the use of the intake fraction approach to characterize indoor exposures [17]. First case studies applying occupational exposure models in LCA exists 
[18]. However, an evaluation of these modeling alternatives using exposure measurements has not yet been conducted.

Our goals in this paper are (a) to evaluate modeling alternatives and their capabilities and limitations with regard to occupational exposure questions; (b) to evaluate model performance relative to measurements for a specific and relatively data-rich exposure scenario, and (c) to identify adequate models for standard use in LCA. To achieve this, we provide a qualitative and quantitative evaluation of model alternatives for the case of occupational indoor exposure to VOCs among vehicle repair workers during their use of aerosol spray cans.

\section{METHODS}

Models. The three exposure models we use for this evaluation are a one- and a two-box bulk-mixing model and an eddy-diffusion model. These models are conceptually similar or compatible to environmental exposure models [19-21]. We provide both a qualitative and quantitative evaluation of the capabilities and limitations of each model and also judge its ability to reconstruct and predict actual exposure situations. Model assessment criteria were fidelity (i.e. ability to represent the exposure situation), reliability (i.e. precision and accuracy), and transparency (i.e. ability in conveying emissions-exposure relationships).

The models used in this study have been described elsewhere [7, 8, 16, 17]. A brief description of the model principles and equations used is included here and in Table 1. Table 1 also includes model parameter values derived from monitoring data and those obtained by other methods. 
- One-box model: The volume of the workplace is modeled as one homogeneouslymixed box. Concentrations are calculated as a function of emission, ventilation rate, and time elapsed from emission start [7].

- Two-box model: When concentration homogeneity throughout the setting does not apply, a subdivision into two conceptual homogeneously-mixed zones with zonespecific concentrations can be used to represent near and far-field exposures $[7,16]$. Additional parameters to be quantified include the geometry and size of the conceptual inner zone, as well as inter-zonal air-exchange rates.

- Eddy-diffusion model: This model is based on turbulent diffusion driving mass transport [7, 14]. Concentrations are modeled as a function of distance from source and time from the onset of emissions [16]. The empirically derived diffusivity, $D$, describes bulk-air movement caused by ventilation, by the motion of the room's occupants or by turbulence within emission phenomena.

Exposure Data and Experimental Set-Up. We set up the models and their evaluation for an occupational setting with extensive field data gathered in vehicle repair shops under actual working conditions (referred to hereafter as "Worker exposure data") [5] and experimetal data gathered under conditions resembling actual work practices in a vehicle repair shop (referred to hereafter as "Experimental data 1") and in the laboratory (referred to hereafter as “Experimental data 2").

Worker exposure data. Wilson et al. [5] employed qualitative and quantitative methods to characterize VOC exposure among vehicle repair technicians during typical repair tasks. They observed nine technicians in three shops (Sites A-C, Tables S1-S3) that used 
a commercially available "aerosol" product (Product \#1) and participated in quantitative exposure measurements. Product \#1 contained hexane, acetone, toluene, methanol, MEK, mixed xylenes, isopropanol, and carbon dioxide (Table S4). Quantitative measurements included task-length, integrated breathing zone $(n=23)$ and area $(n=49)$ samples using $6 \mathrm{~mm}$ charcoal tubes with sampling pumps $(100 \mathrm{ml} / \mathrm{min})$; measurement of the solvent mass emitted during each task $(n=23)$; continuous measurement sampling of breathing zone (BZ) VOC's ( $n=1,238$, measured during the performance of 26 tasks) using a Hnu photoionization detector (concentrations from this are in pentane-equivalent units); and measurement of air speed in the work areas $(n=780$, measured during the performance of 26 tasks) using a thermal anemometer. The BZ air exchange rate was estimated using the continuous sampling data. The BZ and area samples were obtained at distances of 0.4 and 2-8 $\mathrm{m}$ from the brake assembly, respectively (Figure S1a). Charcoal tubes were extracted in carbon disulfide and analyzed by gas chromatography. Wilson et al. $[4,5]$ provide detailed descriptions of sampling conditions and methods, laboratory methods, data analysis and results. The results of the Worker Exposure Data were used to assess the model effectivenss in predicting exposure during a task over a long period of time.

Experimental data 1. To further characterize exposures to VOCs among vehicle repair technicians during the use of Product \#1, Wilson et al. constructed a measuring station $1.4 \mathrm{~m}$ above floor level and $0.4 \mathrm{~m}$ from the vehicle axle's outer edge to simulate the approximate location of the technician's breathing zone during brake maintenance work. They performed eight tests over two weekend days at a vehicle repair shop when workers were not present and the shop doors were closed. During these trials, $537 \mathrm{~g}$ aerosol spray cans of Product \#1 were held at the customary level for brake repair work. At time $\mathrm{t}=0$ 
$\mathrm{s}$, the aerosol can activator was depressed for $30 \mathrm{~s}$, delivering solvent to the brake assembly at the rate observed in the ten shops (Table S5). Experimental data 1 measurements were only performed at Site A. Experimental dataset 1 was used to compare exposure measurements to model results.

Experimental data 2. The second set of experiments, Experimental data 2, were developed and conducted in the laboratory to quantify solvent distribution during spraying, solvent emission rates and air velocities at the inter-zonal exchange zone. Similar to Experimental data 1, spraying cans of Product \#1 were used. However, the solvent composition differed (Table S4). The vapor pressure of the new formulation was estimated as $81 \%$ of the old formulation (Table S4), and all the expelled solvent evaporated for both solvent mixtures. Therefore, exposure concentration differences resulting from composition differences were not expected and no adjustment corrections were made.

Experimental data 2 measured the fractions of brake cleaner adhering to the brake and lost due to drip-off and overspray. The experimental set up consisted of a 21 -cm-diameter ring representing the equivalent brake size [22], supported on a stand (Figure S2). The ring was covered with Whatman filter paper to retain the solvent. While this may overestimate retention on the brake (due to the absorbance capacity of the paper filter compared to grease on a metal brake) it serves as a bounding estimate of exposure levels. A 21-cm-diameter dish positioned underneath the ring collected drip-off. Both the simulated-brake construction and collecting dish were placed on separate balances, monitoring weight changes at $1 \mathrm{~s}$ intervals, before, during and after spraying while 
solvent evaporation occurred. The aerosol can was weighed before and after each spraying session, allowing estimation of overspray from the mass balance.

Experimental data 2 also included the air-velocity measurements of the solvent aerosol stream at twelve positions from the source (Figure S1b) using a thermal anemometer, VelociCalc Plus (TSI Inc.). Measurements were carried out over 5-s spraying periods.

Finally, the solvent evaporation rate, $G_{\text {evap }}$, was estimated from the decreasing-withtime mass curves from the collecting dish and the simulated-brake. A constant evaporation rate was assumed as a simplification, based on the time required for $75 \%$ mass loss.

\section{RESULTS}

Exposure Conditions (Worker exposure data). During the monitored tasks solventspraying periods lasted between 30-90 s [4, 5]. Figure S1a displays the measuring positions and distances for which integrated solvent exposure concentrations were measured $[4,5]$, while Figure S1c shows the spatial concentration profile as percentages of the maximum observed value of the concentrations recorded in each position $[4,5]$. Real-time breathing-zone concentrations peaked at $394 \mathrm{mg} / \mathrm{m}^{3}$ at $60-75$ seconds after the initiation of spraying [5].

Exposure Conditions (Experimental data 1). The trial measurements produced higher concentrations, reaching $634 \mathrm{mg} / \mathrm{m}^{3}$ in the BZ. These likely reflect higher-end exposures that result during working conditions when air movement and turbulence from the movements of other workers are both mimimal. The VOC temporal concentration profile (Figures 2a-c and S2) shows a steady increase in concentration during spraying. 
Immediately after spraying stops, we see a significant drop in concentration during the first $45 \mathrm{~s}$, followed by a slower decline to background concentration levels [4].

Effective Ventilation Rate. Solvent removal was estimated from Experimental data 1 after emissions stopped. Over the duration of the VOC removal period $(t>30 s)$, the airexchange rate was $0.16 \mathrm{~min}^{-1}$. However, segregating the VOC decline period into 2 phases (Figure S3) produces two distinctly different effective air-exchange rates within the vicinity of emission, namely $2.0 \mathrm{~min}^{-1}$ for $\mathrm{t}=30 \mathrm{~s}$ to $\mathrm{t}=75 \mathrm{~s}$ and $0.13 \mathrm{~min}^{-1}$ afterwards until background is reached $(\mathrm{t}=675 \mathrm{~s})$.

To test the predictive power of the models when detailed parameter values are not available, literature values for air-exchange rates in occupational settings were also used (Table 1). Non-mechanically ventilated environments have typically less than 1 exchange/h, whereas in settings with mechanical ventilation values of 3-20 exchanges $/ \mathrm{h}$ are reported $[23,24]$. For typical ventilation rates, we used values from 0.5 exchanges $/ \mathrm{h}$ (typical for non-mechanically ventilated rooms) up to 5 exchanges/h. The high values are justified for the Worker Exposure Data setting, as here one wall of doors was kept open during working [4] (see Methods).

Solvent Distribution (Experimental data 2). The VOC mass distribution showed a relatively constant allocation and was independent of the mass sprayed. Over 7 trials, $13.8 \% \pm 2.3 \%$ of the mass sprayed was retained on the brake, $27.5 \% \pm 15.9 \%$ was lost as drip-off, and overspray to the surrounding air amounted to $58.7 \% \pm 16.1 \%$ (see Methods, Experimental Data 2, and Figure S2).

Emission Rates. Based on Experimental data 1 Wilson et al [5] reported that, for a $30 \mathrm{~s}$ spraying period, the average amount of brake cleaner emitted as VOCs was $116 \mathrm{~g}$. This 
corresponds to a constant emission rate of $3.87 \mathrm{~g} / \mathrm{s}$. The emission rate $\mathrm{G}$ can be represented as two vectors, consisting of direct emissions to air, $G_{\text {direct }}$, and those from evaporation from the brake and drip pan, $G_{\text {evap }}\left[\mathrm{G}=G_{p u l s e}=G_{\text {evap }}+G_{\text {direct }}(\right.$ for $\left.\mathrm{t} \leq 30 \mathrm{~s})\right]$. After 30 seconds, spraying ceases and emissions are reduced to evaporation only $\left(\mathrm{G}=G_{\text {evap }}\right.$ for t>30 s). Considering the solvent distribution pattern determined above (Section Experimental Data 2 and Section Sovlent Distribution, Figure S2), the average amount of VOCs emitted during a $30 \mathrm{~s}$ spraying period (116 g) results in $68 \mathrm{~g}$ on average being directly emitted to the surrounding air as overspray in the first $30 \mathrm{~s}$, while the remaining $48 \mathrm{~g}$ is deposited on the brake assembly and collected from drip-off, and then evaporates into the workplace. A linear fit to the the mass evaporation data (see Methods Experimental data 2; Figure S4) resulted in a relatively good estimation of a constant emission rate of $0.0265 \pm 0.0129 \mathrm{~g} / \mathrm{s}\left(r^{2}=0.60\right)$.

Aerosol Velocity in Indoor Air (Experimental Data 2). The measurements of air-mass velocity revealed significantly elevated air velocities during spraying compared to background in the region surrounding the emission source (Figure S5). Overall, the average air velocity was $0.40 \pm 1.12 \mathrm{~m} / \mathrm{s}$ and $0.12 \pm 0.35 \mathrm{~m} / \mathrm{s}$, during spraying and under background conditions, respectively. A two-sided student t-test showed air velocities at P1 to P4 and P1" to P4" (Figure S1b) to be statistically different from background at the 99\% confidence interval. Mean air velocity during spraying in these positions were $0.86 \pm 1.79 \mathrm{~m} / \mathrm{s}$ and $0.19 \pm 0.18 \mathrm{~m} / \mathrm{s}$, respectively. Maximum air velocity during spraying at $\mathrm{P} 1$ to $\mathrm{P} 4$ and $\mathrm{P} 1$ ' to $\mathrm{P} 4$ ' (Figure $\mathrm{S} 1 \mathrm{~b}$ ) reached 9.2 and $0.66 \mathrm{~m} / \mathrm{s}$, respectively. Therefore, the nature of the emission produces significantly different conditions of turbulence during spraying. 
Exposure Models. We evaluated each model for its ability to match the magnitude, temporal profile and the time-integrted measured concentrations. To ensure that we capture a reasonable upper bound on exposure, we use Experimental-data-1 breathing zone results for our comparison to the model predictions (see Section Exposure Conditions (Experimental data 1)). For reproducing exposure data, we used solvent distribution, emission rates, effective ventilation rates for the inner zone, and air velocities as illustrated above. To test the predictive power of the models, we also used parameter values from the literature (Table 1).

One-box model. Monitored solvent values (Figure S1c) indicate a significant spatial stratification with distance from the emission $[4,5]$. Nevertheless, we first calculated the temporal concentration profile using a one-box model, which lacks spatial resolution (Figure 1a), in order to assess the reliability of a simple baseline model [17]. Figure 1a provides four different model estimations. The first three models ( $\mathrm{M} 0_{\text {one-box }}, \mathrm{M} 1_{\text {one-box }}$ and $\mathrm{M} 2_{\text {one-box }}$ ) show the temporal concentration profile using a constant emission rate, but different ventilation rates (Table 1 ). $\mathrm{M} 0_{\text {one-box }}$ uses ventilation rates from the literature and therefore serves as an example for predictive modeling. $\mathrm{M} 1_{\text {one-box }}$ uses an averaged ventilation rate obtained from Experimental data 1. In $\mathrm{M} 2_{\text {one-box }}$, the effective ventilation during 0-75 s, i.e., during spraying and the initial decline phase, was used (Table 1). In a fourth model, $\mathrm{M} 3_{\text {one-box }}$, the same settings as in $\mathrm{M} 2_{\text {one-box }}$ were used, but the emission rate was variable (Table 1). In all cases, the breathing concentration of the workers is underestimated during the first $75 \mathrm{~s}$ of exposure. During the entire task, exposure is slightly overestimated by a factor of 1.3 for $\mathrm{M} 0_{\text {one-box }}$. For $\mathrm{M} 1_{\text {one-box }}-\mathrm{M} 3_{\text {one-box }}$ the near- 
field exposure over the entire task is underestimated by factor of 1.5, 6.4, and 1.3, respectively.

The one box model was then applied to a longer-term task (1.5 hours) consisting of repair on all four brakes of a car. A range of air-exchange rates between 0.5 and $5 \mathrm{~h}^{-1}$ was used (Section Effective ventilation rates). Figure 1d shows the modeled exposure conditions for the break inspection task IS-2 (Tables S1-S2) over 1.5 hours. An airexchange rate of $3 \mathrm{~h}^{-1}$ was used in the graph. In this case, the exposure concentration modeled was higher by approximately $33 \%$ and $10 \%$ of the BZ TWA-measured concentration, for the constant ( $\left.\mathrm{M} 4_{\text {one-box }}\right)$ and variable ( $\left.\mathrm{M} 5_{\text {one-box }}\right)$ emission rates, respectively (Table 1). The far-field workers' exposure is overestimated by a factor of 16 and 13 in $\mathrm{M}_{\text {one-box }}$ and $\mathrm{M} 5_{\text {one-box }}$, respectively. Therefore, the model would have provided a conservative but not unreasonably high estimation of exposure.

Two-box model. In a next step, an inner zone is used to provide more model detail and capture the elevated concentrations in the BZ. The Worker exposure data was considered in defining the size and geometry of the inner zone. Total VOC monitoring at $2 \mathrm{~m}$ from the source indicates that concentrations could be within $50 \%$ of the maximum levels in the BZ (Figure S1c). Additionally, the workers movements result in setting the innerzone as a hemisphere with a radius of $1.5 \mathrm{~m}$, and an inner-zone volume of $7.1 \mathrm{~m}^{3}$. The air-exchange rate between inner and outer zones was approximated by calculating the product of the mean air velocity from Experimental data 2 and the free surface area through which exchange can occur [8]. Air velocity measurements indicate that conditions were different during and after spraying. In the first instance the average constant emission rate of $3.87 \mathrm{~g} / \mathrm{s}$ is used, with the high inter-zonal exchange rate of 2.84 
$\mathrm{m}^{3} / \mathrm{s}$ during spraying and for the first $45 \mathrm{~s}$ post-spraying. For the $\mathrm{BZ}$ concentration this model calculation ( $\mathrm{M} 1_{\text {two-zone }}$ ) overestimates the $\mathrm{BZ}$ exposure levels by a factor of 2.2 (Figure 1b), whereas the far-field concentration is approximately $15 \%$ of the inner-zone. The modeled far-field integrated VOC concentration is within the range of the TWA area samples measured (on average, $38 \%$ of BZ concentrations at 2-4 m and approximately $5 \%$ of BZ concentrations at $8 \mathrm{~m}$, Table S1) [4].

In a second estimation $\left(\mathrm{M} 2_{\text {two-zone }}\right)$ the same parameter values are used except for the emission rate, which was segregated into two vectors (smilar to $\mathrm{M}_{\text {one-box, }}$, Table 1). This model more closely captures the magnitude of the BZ exposure level but underestimates exposures following spraying when concentration is rapidly declining. The same model conditions were then used to model the integrated exposure over task IS-2 (Table S2). The case of $\mathrm{M} 3_{\text {two-box }}$ is shown in Figure 1e. Over the entire task, $\mathrm{M} 3_{\text {two-box }}$ overestimates the measured exposures in the near and far fields by a factor of approximately 2 and 10 , respectively. Using the variable emission rate to estimate the integrated exposure over task IS-2 gives a very good agreement for the near-field exposure (modeled $\mathrm{C}_{\mathrm{NF}}=0.08 \mathrm{~g} / \mathrm{m}^{3}$ and measured $\left.\mathrm{C}_{\mathrm{BZ}}=0.0825 \mathrm{~g} / \mathrm{m}^{3}\right)$.

Eddy-diffusion model. The diffusivity, $D$, was obtained from the Worker exposure data concentration ratios at two different times $\left(t_{1}=15 \mathrm{~s}\right.$ and $t_{2}=30 \mathrm{~s}$ ), using equation 4 (Table 1). This resulted in $D=0.0028 \mathrm{~m}^{2} / \mathrm{s}$. Using the mechanical energy balance [16] resulted in $D=0.163 \mathrm{~m}^{2} / \mathrm{s}$ (Table S6). Inserting both of these values into eq. 4 , resulted in modeled concentrations that were an order of magnitude higher than those measured during the Experimental-data-1 experiments. Using eq. 4 and the concentration measurments for the time $\mathrm{t}=30 \mathrm{~s}$ of Experimental data 1 (Table S7) resulted in a diffusivity of $0.66 \mathrm{~m}^{2} / \mathrm{s}$. This 
value along with the variable emission rate (Table 1) was used in eq. 5 to model VOC concentrations ( $\left.\mathrm{M} 1_{\text {eddy-diffusion}}\right)$, according to the approach of Nicas and Armstrong [25]. A time-step resolution of $0.1 \mathrm{~s}$ was used (Figure S6). For this approach, the time-integrated average concentration modeled of $280 \mathrm{mg} / \mathrm{m}^{3}$ and measured TWA exposure levels of 240 $\mathrm{mg} / \mathrm{m}^{3}$ are in good agreement, although the temporal profiles did not resemble each other well.

The eddy-diffusion model has notable advantages over the bulk-mixing models because it can account for continuous concentration gradients with both time and distance $[14,26]$. The ratios of the modeled concentration-to-emission rates, $\mathrm{C}_{\mathrm{avg}}(\mathrm{r}) / \mathrm{G}$, were compared to those of the measured Worker exposure data integrated area samples (Figure 1f). The model overestimated the $B Z$ concentration, but approximated the mean measured concentrations at 2 to $4 \mathrm{~m}$ and at $8 \mathrm{~m}$ reasonably well. One likely reason for the difference in BZ concentration is that the model parameters were based on Experimental data 1 values, which had decreased air movement or turbulence in comparison to Workers exposure data (see Methods).

\section{DISCUSSION}

A previous qualitative assessment of exposure models showed that the three models evaluated here are compatible with the criteria and degree of detail of the environmental exposure models used for the assessment of human-health effects in LCA [17]. These models can be easily integrated into the current LCA framework. The applicability of box models within LCA has already been demonstrated for occupational exposure [18], as has the use of multi-box models for residential exposure [27, 28]. The qualitative assessment identifies the available options, whereas the quantitative assessment of their application 
performed here allows for the demonstration, evaluation, and selection of appropriate models.

In applying the three criteria of fidelity, reliability, and transparency to the model evaluation, we make the following observations. The one-box model provides the highest level of transparency and ease of use, but lacks inherent fidelity with respect to spatially differentiated exposures $[8,29]$. The fidelity and reliability of the two-box model in predicting the magnitude of the BZ exposure concentration are quite high. This is especially important because the model parameter values, apart from the effective ventilation rate, were estimated from a different experimental dataset and not from the measured Experimental data 1 values. The eddy-diffusion model ranks high with regard to fidelity because of its ability to distinguish near versus far-field exposure and to model concentration gradients both with time and distance from the emission source. Reliability is an issue for all models because they must be calibrated to optimize their performance with respect to field data. For example, in spite of its inherently better fidelity, the eddydiffusion model lacks reliability because of the need to calibrate the diffusion parameter D.

Recent studies examining the use of the same types of models in a range of indoor environments, have demonstrated their applicability, usefulness and predictive power by evaluating model performance with measured concentrations [30-32]. However, a number of studies investigating and evaluating model performance utilize measured data from existing studies $[9,13,14,33,34]$ or data from controlled experiments $[6,10]$. Moreover, studies that provide measurements or apply measurements from existing studies show that in many cases the database is not sufficiently comprehensive $[13,14]$. The present study has the advantage of utilizing a relatively large amount of empirical 
data from monitoring studies in real settings and trial experiments in the same settings, or with the same product, to quantify as many model parameters as possible. Despite this rich data set, we demonstrate that the uncertainty of the models evaluated here can be quite large as previously seen $[10,35]$. In the eddy-diffusion model, values for $D$ must be fitted to the actual exposure data or obtained from the small number of empirical studies that have been published [12, 14-16, 36, 37]. For instance, Wadden et al. [14] determined $D$ to be between 0.0016 and $0.027 \mathrm{~m}^{2} / \mathrm{s}$ in a metal-degreasing facility. Our diffusivity ranged from 0.0028 to $0.66 \mathrm{~m}^{2} / \mathrm{s}$, and was therefore higher than the values reported in the literature $[12,14-16,36,37]$. One reason for this is that the $D$ estimation is based on measurement data during the spraying time and in the close vicinity to the source. The air velocity measurements performed during the Experimental data 2 experiments showed that velocities were more than an order magnitude higher during spraying than background conditions. Eddies transport mass, so an increase of air velocity associated with bulk movement will increase mass transport and reduce concentration gradients around the source. This illustrates one of the major drawbacks of generalizing and using default values for sensitive parameters, such as $D$, which display a large degree of variation.

The goal of integrating the assessment of health effects that result from indoor exposures into tools, such as LCA, requires the ability to quantify workers exposures. The models investigated show that over extended time-periods they provide conservative estimates of the exposure levels and are within a factor of 2 of those measured for all cases. This is also the case when literature values on typical ventilation rates are used in the example of the one-box model. This complies with a risk assessment approach of erring on the side of precaution and also allows for their use in LCA studies. 
The key question is whether a standard default, "one-size-fits-all" model, for a first step in a tiered approach of assessing human-health impacts from indoor exposure is appropriate in RA and LCA. One might consider a homogeneously mixed-box model as a first step in identifying the need for a more detailed investigation for a specific indoor environment [17]. The approximation of evenly distributed pollutant concentrations in indoor air is common [38], a practice that supports use of the one-box model. It is simple to use, has low input requirements, and demonstrates the relationship of emission-toexposure reasonably well in cases of equal dispersion $[6,9,10,13]$. In the present case, while an examination of the first $100 \mathrm{~s}$ of exposure consistently underestimated the exposure, the time-integrated modelled levels provided better estimates. A similar picture is seen for the two-box model, which tended to overestimate the observed BZ concentration in the short time-frame but provided good estimates of the time-integrated exposure conditions.

We have produced a detailed experimental study to evaluate the performance of exposure models that can be used to address indoor exposures in comparative assessments. While this is a comprehensive study of one specific setting, the vast range of workplaces and exposure conditions requires an extensive qualitative assessment of the applicability of these models over a number of occupational environments. Future research on this issue should focus on the determination of parameter values and their distribution ranges in various types of indoor environments, using carefully controlled experimental conditions [39]. The current lack of data on indoor parameters of various settings calls for the need to build databases that would provide ranges of all necessary values for model application. Such work would facilitate probabilistic exposure modeling in indoor air quality practice (Figure S7), especially in cases where measurements are 
difficult to perform. It would also allow investigators to assess and compare occupational and other indoor and outdoor exposure concentrations (and potential health effects) as applied with various assessment tools, such as LCA. Ranking results obtained with model calculations can be a useful input to comparative assessments, despite the relatively low confidence in the absolute value of exposure estimates [42]. As more field data become available, we expect indoor mass balance models will become important tools in the LCA decision making process.

\section{ACKNOWLEDGMENTS}

E. Demou would like to thank Dr. Daniel Braun and Fabienne Steiner for their assistance in setting up the experiments at ETH Zurich. S. Hellweg gratefully acknowledges funding from the Swiss National Science Foundation (Grant PIOI2-107292/1). T. McKone was supported in part by the US EPA National Exposure Research Laboratory through Interagency Agreement No. DW-988-38190-01-0, with the Lawrence Berkeley National Laboratory operated for the US Department of Energy (DOE) under Contract Grant No. DE-AC02-05CH11231 and by Cooperative Agreement Number U19/EH000097-02 from the US Centers for Disease Control and Prevention (CDC). Michael Wilson was supported by the Northern California Education and Research Center of the National Institute for Occupational Safety and Health; the University of California Toxic Substances Research and Teaching Program; and the Hazard Evaluation System and Information Service (HESIS) of the California Department of Health Services.

SUPPORTING INFORMATION AVAILABLE. The supporting information contains detailed information on the formulation and applied mass. The estimation procedures of 
the diffusivity are included. Tables of emission rates and integrated area samples are incorporated.

\section{FIGURE CAPTIONS}

Figure 1. Model comparisons to Experimental data 1 and Task IS-2 of Worker exposure data measured solvent concentrations in the workplace. Grey shaded areas depict spraying time. Model comparisons to Experimental data 1 to the (a) one-box model ; (b)

two-box model; (c) eddy-diffusion model. Model comparisons to time-weighted average (TWA) Worker exposure data to the (d) one-box model; (e) two-box model; (f) VOC Worker exposure data concentrations, normalized by the emission rate, with distance from the emission source compared to modelled concentrations using the eddy-diffusion model.

\section{REFERENCES}

1. Pellizzari, E. D.; Hartwell, T. D.; Perritt, R. L.; Sparacino, C. M.; Sheldon, L. S.; Zelon, H. S.; Whitmore, R. W.; Breen, J. J.; Wallace, L., Comparison of Indoor and Outdoor Residential Levels of Volatile Organic Chemicals in Five U.S. Geographical Areas. Environment International 1986, 12, 619-623.

2. Jones-Otazo, H. A.; Clarke, J. P.; Diamond, M. L.; Archbold, J. A.; Ferguson, G.; Harner, T.; Richardson, G. M.; Ryan, J. J.; Wilford, B., Is house dust the missing exposure pathway for PBDEs? An analysis of the urban fate and human exposure to PBDEs. Environmental Science \& Technology 2005, 39, 5121-5130.

3. Nazaroff, W. W., Inhalation intake fraction of pollutants from episodic indoor emissions. Building and Environment 2008, 43, 269-277.

4. Wilson, M. n-Hexane Exposure in the California Vehicle Repair Industry: Risk Assessment and Policy Analysis. Ph.D. thesis, University of California at Berkeley, Berkeley, 2003.

5. Wilson, M. P.; Hammond, S. K.; Nicas, M.; Hubbard, A. E., Worker exposure to volatile organic compounds in the vehicle repair industry. Journal of Occupational and Environmental Hygiene 2007, 4, 301-310.

6. Keil, C., The Development and Evalutation of an Emission Factor for Toluene Parts-Washing Process. AIHA Journal 1998, 59, 14-19.

7. Keil, C., A Tiered Approach to Deterministic Models for Indoor Air Exposures. Applied Occupational and Environmental Hygiene 2000a, 15, 145-151. 
8. Nicas, M., Estimating Exposure Intensity in an Imperfectly Mixed Room. AIHA Journal 1996, 57, 542-550.

9. Selway, M. D.; Allen, R. J.; Wadden, R. A., Ozone Production from Photocopying Machines. AIHA Journal 1980, 41, 455-459.

10. Vernez, D.; Bruzzi, R.; Kupferschmidt, H.; De-Batz, A.; Droz, P.; Lazor, R., Acute respiratory syndrome after inhalation of waterproofing sprays: A posteriori exposure-response assessment in 102 cases. Journal of Occupational and Environmental Hygiene 2006, 3, 250-261.

11. von Grote, J.; Hürlimann, C.; Scheringer, M.; Hungerbühler, K., Reduction of the Occupational Exposure to Perchloroethylene and Trichloroethylene in Metal Degreasing over the Last 30 Years - Influences of Technology Innovation and Legislation. Journal of Exposure Analysis and Environmental Epidemiology 2003, 13, 325-340.

12. Cherrie, J. W.; Schneider, T., Validation of a new method for structured subjective assessment of past concentrations. . Ann Occup Hyg 1999, 43, 235-245.

13. Nicas, M., Estimating Methyl Bromide Exposure Due to Offgassing from Fumigated Commodities. Applied Occupational and Environmental Hygiene 2003, 18, 200-210.

14. Wadden, R. A.; Scheff, P. A.; Franke, J. E., Emission Factors for Trichloroethylene Vapor Degreasers. . AIHA Journal 1989, 50, 496-500.

15. Drivas, P.; Sommonds, P.; Shiar, F., Experimental characterization of ventilation systems in buildings. Environmental Science and Technology 1972, 6, 733-741.

16. Keil, C., Mathematical Models for Estimating Occupational Exposure to Chemicals. American Indsutrial Hygiene Association: 2000b.

17. Hellweg, S.; Demou, E.; Bruzzi, R.; Meijer, A.; Rosenbaum, R. K.; McKone, T.

E.; Huijbregts, M., Integrating Indoor and Outdoor Pollutant Exposure within Comparative Environmental Assessments. (submitted).

18. Hellweg, S.; Demou, E.; Scheringer, M.; McKone, T.; Hungerbuehler, K., Confronting Workplace Exposure to Chemicals with LCA: The Examples of Trichloroethylene and Tetrachloroethylene in Metal-Degreasing and Dry-Cleaning. Evnironmental Science and Technology 2005, 39, 7741-7748.

19. Huijbregts, M. A. J. Priority Assessment of Toxic Substances in the Frame of LCA-The Multi-Media Fate, Exposure and Effect Model USES-LCA; University of Amsterdam (NL): Amsterdam, 1999.

20. McKone, T. E.; Enoch, K. CalTox, A multimedia total exposure model. http://eetd.lbl.gov/ied/ERA/caltox/, 2002.

21. Rosenbaum, R. K.; Bachman, T. K.; Hauschild, M. Z.; Huijbregts, M. A. J.; Jolliet, O.; Juraske, R.; Köhler, A.; Larsen, H. F.; Macleod, M.; Margni, M.; McKone, T. E.; Payet, J.; Schuhmacher, M.; Russel, A.; Van de Meent, D., USETox-The UNEP/SETAC-consensus model: recommended characterization factors for human toxicity and freshwater ecotoxicity in Life Cycle Impact Assessment. International Journal of LCA submitted.

22. Schmidt, W.-P., Brake diameter (personal communication). In Vehicle Environmental Engineering, FORD: Köln, 2006. 
23. ExpoFacts, European Exposure Factors Sourbook. In PCE Unit at the Joint Research Centre of the European Commission in Ispra: 2006.

24. Heinsohn, R., Industrial Ventilation: Engineering Principles. 10th Edition ed.; John Wiley \& Sons, Inc.: New York/ Chichester/ Brisbane/ Toronto/ Singapore, 1991; p 699.

25. Nicas, M.; Armstrong, T. W., Using a spreadsheet to compute contaminant exposure concentrations given a variable emission rate. AIHA Journal 2003, 64, 368-375.

26. Roach, S. A., On the Role of Turbulent-Diffusion in Ventilation. Ann Occup Hyg 1981, 24, 105-132.

27. Meijer, A., Human Health Damages due to Indoor Sources of Organic Compounds and Radioactivity in Life Cycle Assessment of Dwellings - Part 1: Characterization Factors. International Journal of Life Cycle Assessment 2005 a, 5, 309316.

28. Meijer, A., Human Health Damages due to Indoor Sources of Organic Compounds and Radioactivity in Life Cycle Assessment of Dwellings - Part 2: Damages sources. International Journal of Life Cycle Assessment 2005 b, 6, 383-392.

29. Nicas, M., The effect of concentration gradients on deducing a contaminant generation rate function. AIHA Journal 1998, 59, 680-688.

30. Keil, C.; Murphy, R., An application of exposure modeling in exposure assessments for a university chemistry teaching laboratory. Journal of Occupational and Environmental Hygiene 2006, 3, 99-106.

31. Klepeis, N. E.; Nazaroff, W. W., Modeling residential exposure to secondhand tobacco smoke. Atmospheric Environment 2006, 40, 4393-4407.

32. Spencer, J. W.; Plisko, M. J., A comparison study using a mathematical model and actual exposure monitoring for estimating solvent exposures during the disassembly of metal parts. Journal of Occupational and Environmental Hygiene 2007, 4, 253-259.

33. Drivas, P. J.; Valberg, P. A.; Murphy, B. L.; Wilson, R., Modeling indoor air exposure from short-term point source releases. Indoor Air-International Journal of Indoor Air Quality and Climate 1996, 6, 271-277.

34. Nicas, M., Modeling turbulent diffusion and advection of indoor air contaminants by Markov chains. AIHA Journal 2001, 62, 149-158.

35. Boucher, R.; Hanna, C.; Rusch, G. M.; Stidham, D.; Swan, E.; Vazquez, M., Hepatotoxicity associated with overexposure to 1,1-dichloro-2,2,2-trifluoroethane (HCFC-123). AIHA Journal 2003, 64, 68-79.

36. Jayjock, M., Modelling Inhalation Exposure. In:. AIHA: Fiarfax, 1997; p 69 - 74.

37. Scheff, P. A.; Friedman, R. L.; Franke, J. E.; Conroy, L. M.; Wadden, R. A., Source activity modeling of Freon emissions from open-top vapor degreasers. Applied Occupational and Environemtnal Hygiene 1992, 7, 127-134.

38. Drescher, A.; Lobascio, C.; Gadgil, A.; al., e., Mixing of a point source indoor pollutant by forced convection. Indoor Air 1995, 5, 204-214.

39. Bruzzi, R. New developments and applications in modelling occupational exposure to airborne contaminants. University of Lausanne, Lausanne, 2007. 
40. Tielemans, E.; Noy, D.; Schinkel, J.; Heussen, H.; Van der Schaaf, D.; West, J.; Fransman, W., Stoffenmanager exposure model: Development of a quantitative algorithm. Annals of Occupational Hygiene 2008, 52, 443-454.

41. Marquart, H.; Heussen, H.; Le Feber, M.; Noy, D.; Tielemans, E.; Schinkel, J.; West, J.; Van der Schaaf, D., 'Stoffenmanager', a web-based control banding tool using an exposure process model. Annals of Occupational Hygiene 2008, 52, 429-441.

42. Bruzzi, R.; Vernez, D.; Droz, P. O.; De Batz, A., Beliefs and practices in the assessment of workplace pollutants. Sozial-Und Praventivmedizin 2006, 51, 5-13. 
Figure 1
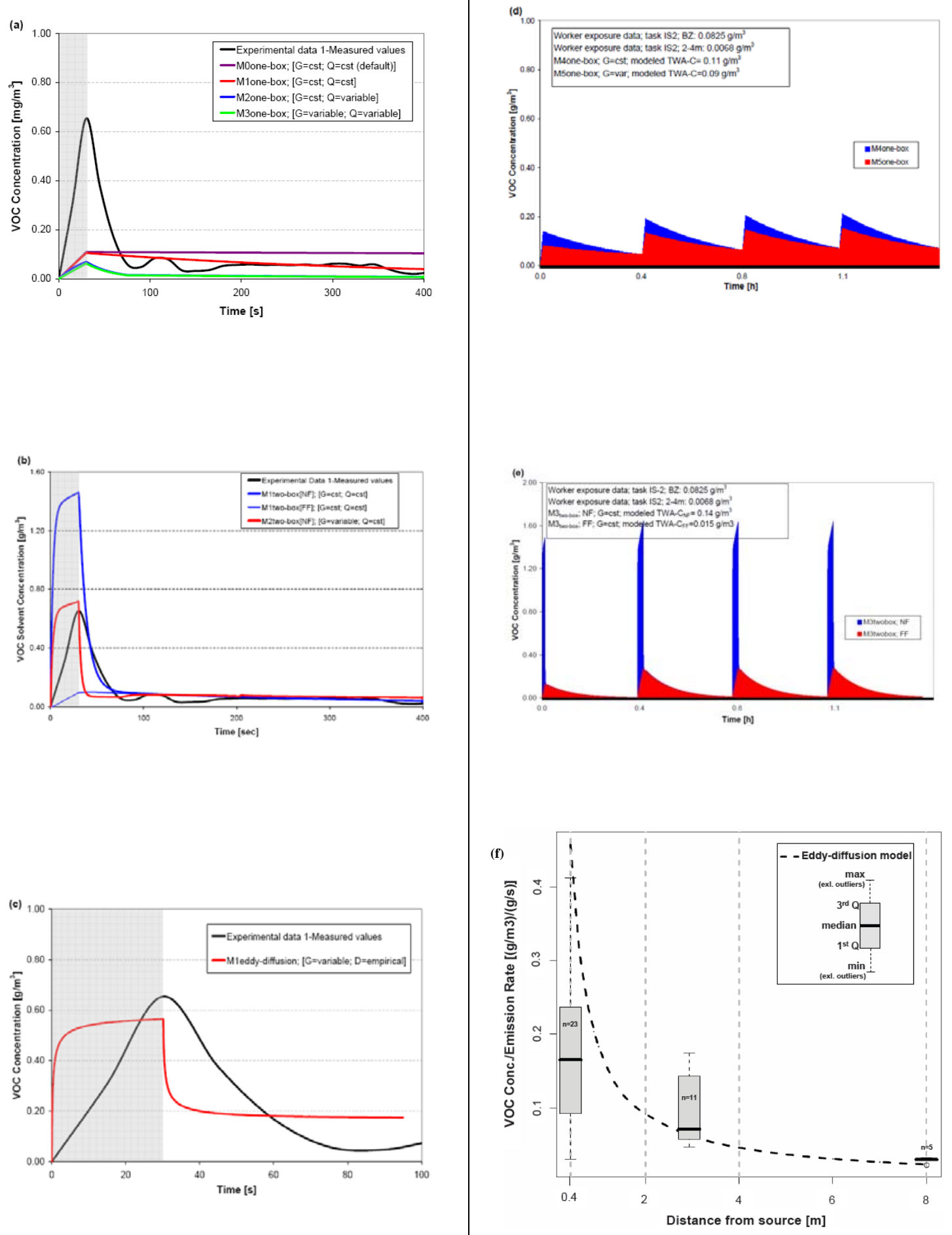
Table 1. Model equations and parameter values used in the model estimations

\begin{tabular}{|c|c|c|c|}
\hline & Model Basic Equations & Parameter Values & Parameter Estimation Method \& Details \\
\hline \multirow{23}{*}{ 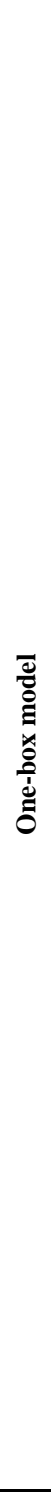 } & \multirow{23}{*}{$\begin{array}{l}C_{t}=\frac{G}{Q}\left[1-e^{-\frac{Q \cdot \Delta t}{V}}\right] \quad E q .1 \\
\text { where } \\
\text { C: Concentration }\left[\mathrm{g} / \mathrm{m}^{3}\right] \\
\text { G: emission rate }[\mathrm{g} / \mathrm{s}] \\
\text { Q: ventilation rate }\left[\mathrm{m}^{3} / \mathrm{s}\right] \\
\text { V: workplace volume }\left[\mathrm{m}^{3}\right]\end{array}$} & M0 one-box $_{\text {- }}$ & Reference: [16] \\
\hline & & $\mathrm{G}=3.87 \mathrm{~g} / \mathrm{s}$ & $\begin{array}{l}\text { Average constant emission rate based on the average amount of solvent } \\
\text { emitted }(116 \mathrm{~g}) \text { during the average spraying time }(30 \mathrm{sec}) \text {. Data source: } \\
\text { Experimental data } 1[4,5]\end{array}$ \\
\hline & & $\begin{array}{l}\mathrm{V}=1064 \mathrm{~m}^{3} \text { (for all one-box models } \\
\mathrm{M} 0_{\text {one-box }} \text { to } \mathrm{M} 5_{\text {one-box }} \text { ) }\end{array}$ & Workplace volume of Site A. Data source: Experimental data 1 [4] \\
\hline & & $\mathrm{Q}=0.14 \mathrm{~m}^{3} / \mathrm{s}$ & $\begin{array}{l}\text { Based on literature values of non-mecahnically ventilated settings } \\
\left(k=0.5 \mathrm{~h}^{-1} \text { or } 0.008 \mathrm{~min}^{-1}\right)[23,24]\end{array}$ \\
\hline & & $\mathrm{G}=3.87 \mathrm{~g} / \mathrm{s}$ & v.s. (see above) \\
\hline & & $\mathrm{V}=1064 \mathrm{~m}^{3}$ & v.s. \\
\hline & & $\mathrm{Q}=2.84 \mathrm{~m}^{3} / \mathrm{s}$ & $\begin{array}{l}\text { Estimated from the air-exchange rate }\left(k=0.16 \mathrm{~min}^{-1}\right) \text { derived from the } \\
\text { VOC declining phase of the concentration curve with time from the end of } \\
\text { spraying until end of measurment period. Data source: Experimental data } \\
1\end{array}$ \\
\hline & & $\mathbf{M} 2_{\text {one-box }}$ & Reference: $[16]$ \\
\hline & & $\mathrm{G}=3.87 \mathrm{~g} / \mathrm{s}$ & v.s. \\
\hline & & $\mathrm{Q}=2.84 \mathrm{~m}^{3} / \mathrm{s}(\mathrm{t}=75$-end $)$ & v.s. \\
\hline & & $\mathrm{Q}=35.5 \mathrm{~m}^{3} / \mathrm{s}(\mathrm{t}=0-75 \mathrm{sec})$ & $\begin{array}{l}\text { Estimated from the VOC concentration curve with time from spraying end } \\
(\mathrm{t}=30 \mathrm{sec}) \text { to time required for aerosol concentration to return to } \\
\text { background conditions }(\mathrm{t}=45 \mathrm{sec}) ; k=2.0 \mathrm{~min}^{-1} \text { Data source: Experimental } \\
\text { data } 1\end{array}$ \\
\hline & & M3 $3_{\text {one-box }}$ & Reference: $[16]$ \\
\hline & & $\mathrm{G}_{\text {direct }}=2.27 \mathrm{~g} / \mathrm{s}($ first $30 \mathrm{~s})$ & $\begin{array}{l}\text { Estimated from the total emission of }(116 \mathrm{~g}) \text { during the average spraying } \\
\text { time and solvent distribution for the spraying period }(58.7 \% \text { emitted } \\
\text { directly to air as overspray). Data source: Experimental data } 1 \& 2\end{array}$ \\
\hline & & $\mathrm{G}_{\text {evaporation }}=0.0265 \mathrm{~g} / \mathrm{s} \quad(\mathrm{t}=0$-end $)$ & $\begin{array}{l}\text { Estimated from solvent distibution (Experimental data 2) of } 41.3 \% \text { sticking } \\
\text { to the brake and dripping of. Data source: Experimental data } 1 \& 2\end{array}$ \\
\hline & & $\mathrm{Q}=35.5 \mathrm{~m}^{3} / \mathrm{s}(\mathrm{t}=0-75 \mathrm{sec})$ & v.s. \\
\hline & & $\mathrm{Q}=2.3 \mathrm{~m}^{3} / \mathrm{s}(\mathrm{t}=75 \mathrm{sec}-\mathrm{end})$ & v.s. \\
\hline & & M4 $4_{\text {one-box }}$ & \\
\hline & & $\mathrm{G}=3.87 \mathrm{~g} / \mathrm{s}($ emission duration $=39 \mathrm{~s})$ & $\begin{array}{l}\text { Emission duration was estimated from the amount applied during task IS } 2 \\
\text { (Table S2) and the constant emission rate of } 3.87 \mathrm{~g} / \mathrm{s} \text {. }\end{array}$ \\
\hline & & $\mathrm{Q}=0.9 \mathrm{~m}^{3} / \mathrm{s}$ & $\begin{array}{l}\text { Based on literature values of occupational settings }\left(k=3 \mathrm{~h}^{-1} \text { or } 0.05 \mathrm{~min}^{-1}\right) \\
{[23,24]}\end{array}$ \\
\hline & & M5 one-box $_{\text {. }}$ & \\
\hline & & $\mathrm{G}_{\text {direct }}=2.27 \mathrm{~g} / \mathrm{s}$ (first $\left.30 \mathrm{~s}\right)$ & v.s. \\
\hline & & $\mathrm{G}_{\text {evaporation }}=0.0265 \mathrm{~g} / \mathrm{s} \quad(\mathrm{t}=0$-end $)$ & v.s. \\
\hline & & $\mathrm{Q}=0.9 \mathrm{~m}^{3} / \mathrm{s}$ & v.s. \\
\hline \multirow{16}{*}{ 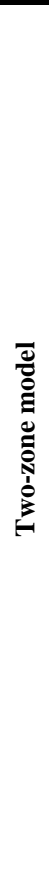 } & \multirow{16}{*}{$\begin{array}{l}\text { Near-field: } \\
V_{N} \cdot d C_{N}= \\
\quad G \cdot d t+\beta \cdot C_{F} \cdot d t-\beta \cdot C_{N} \cdot d t \quad \text { Eq.2 } \\
\text { Far- field: } \\
\begin{array}{l}V_{F} \cdot C_{F}= \\
\quad \beta \cdot C_{N} \cdot d t-(\beta+Q) \cdot C_{F} \cdot d t \quad \text { Eq.3 }\end{array}\end{array}$} & M1 $1_{\text {two-box }}$ & Reference: [16] \\
\hline & & $\mathrm{G}=3.87 \mathrm{~g} / \mathrm{s}$ & v.s. \\
\hline & & $\mathrm{Q}=2.84 \mathrm{~m}^{3} / \mathrm{s}(\mathrm{t}=0-75 \mathrm{sec})$ & v.s. \\
\hline & & $\beta=2.82 \mathrm{~m}^{3} / \mathrm{s}(\mathrm{t}=0-75 \mathrm{sec})$ & $\begin{array}{l}\text { Estimated according to air flow through free surface area } \\
(\beta=1 / 2 \cdot S A \cdot s)[16] \text {, based on hemisphere }(\mathrm{r}=1.5 \mathrm{~m}) \text { surface area }(S A) \\
\text { and air velocity }(s=0.4 \mathrm{~m} / \mathrm{s}) \text {. Data source: Experimental data } 2\end{array}$ \\
\hline & & $\beta=0.85 \mathrm{~m}^{3} / \mathrm{s}(\mathrm{t}=75$ sec-end $)$ & $\begin{array}{l}\text { Estimated as above for air velocity }(\mathrm{s}=0.12 \mathrm{~m} / \mathrm{s}) \text {. Data source: } \\
\text { Experimental data } 2\end{array}$ \\
\hline & & M2 $2_{\text {two-box }}$ & Reference: $[25]$ \\
\hline & & $\mathrm{V}_{\mathrm{N}}=7.1 \mathrm{~m}^{3}$ & $\begin{array}{l}\text { Hesmishpere of a } 1.5 \mathrm{~m} \text { radius. Data source: Workers exposure data \& } \\
\text { Experimental data } 2[5]\end{array}$ \\
\hline & & $\mathrm{V}_{\mathrm{F}}=1056.9 \mathrm{~m}^{3}$ & Remaining workplace volume $\left(\mathrm{V}_{\mathrm{F}}=\mathrm{V}-\mathrm{V}_{\mathrm{N}}\right)$ \\
\hline & & $\mathrm{G}_{\text {direct }}=2.27 \mathrm{~g} / \mathrm{s}$ (first $\left.30 \mathrm{~s}\right)$ & v.s. \\
\hline & & $\mathrm{G}_{\text {evaporation }}=0.0265 \mathrm{~g} / \mathrm{s}(\mathrm{t}>30 \mathrm{~s})$ & v.s. \\
\hline & & $\mathrm{Q}=2.84 \mathrm{~m}^{3} / \mathrm{s}$ & v.s. \\
\hline & & $\beta=2.82 \mathrm{~m}^{3} / \mathrm{s}(\mathrm{t}=0-75 \mathrm{~s}$ & v.s. \\
\hline & & $\beta=0.85 \mathrm{~m}^{3} / \mathrm{s}(\mathrm{t}=75 \mathrm{~s}-\mathrm{end})$ & v.s. \\
\hline & & $\mathbf{M}_{\text {two-box }}$ & \\
\hline & & $\mathrm{G}=3.87 \mathrm{~g} / \mathrm{s}$ (emission duration $=39 \mathrm{~s})$ & v.s. \\
\hline & & $\mathrm{Q}=2.84 \mathrm{~m}^{3} / \mathrm{s}(\mathrm{t}=0-75 \mathrm{sec})$ & v.s. \\
\hline
\end{tabular}




\begin{tabular}{|c|c|c|c|c|}
\hline & & & $\beta=2.82 \mathrm{~m}^{3} / \mathrm{s}(\mathrm{t}=0-84 \mathrm{sec})$ & $\begin{array}{l}\text { The higher interzonal exchange rate is applied for } 45 \mathrm{~s} \text { after spraying ends } \\
\text { as well, due to the increased solvent removal during this period (see } \\
\text { Section Effective Ventilation Rate and Figures S2-S3) }\end{array}$ \\
\hline & & & $\beta=0.85 \mathrm{~m}^{3} / \mathrm{s}(\mathrm{t}=84-1335 \mathrm{sec}$-end $)$ & V.s. \\
\hline \multirow{5}{*}{ 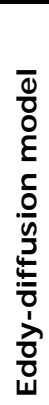 } & \multirow{5}{*}{$\begin{array}{l}C_{t, r}=\frac{G}{4 \pi D r} \cdot\left[1-\operatorname{erf}\left(\frac{r}{\sqrt{4 \cdot D \cdot t}}\right)\right] \\
C_{t, r}=\frac{M}{8 \cdot(\pi \cdot D \cdot t)^{3 / 2}} \cdot e^{-\frac{r^{2}}{4 \cdot D \cdot t}} \quad E q .5 \\
\text { where: } \\
C_{\mathrm{t}, \mathrm{r}}: \text { concentration at time, } \mathrm{t}, \text { and } \\
\text { distance, } \mathrm{r}\left[\mathrm{mg} / \mathrm{m}^{3}\right] \\
\text { D: eddy diffusivity }\left[\mathrm{m}^{2} / \mathrm{s}\right] \\
\text { r: distance from source }[\mathrm{m}]\end{array}$} & \multirow[t]{5}{*}{ Eq.4 } & M1 $_{\text {eddy-diffusion }}$ & Reference: [25] \\
\hline & & & $\mathrm{G}_{\text {direct }}=2.27 \mathrm{~g} / \mathrm{s}($ first $30 \mathrm{~s})$ & v.s. \\
\hline & & & $\mathrm{G}_{\text {evaporation }}=0.0265 \mathrm{~g} / \mathrm{s}(\mathrm{t}=0$-end $)$ & 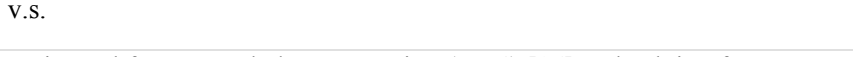 \\
\hline & & & $\mathrm{D}=0.66 \mathrm{~m}^{2} / \mathrm{s}$ & $\begin{array}{l}\text { Estimated from mass balance equation (eq. } 4)[16] \text { and solving for } \mathrm{D} \text { at } \mathrm{t}_{2}= \\
30 \mathrm{~s} \text { at } \mathrm{r}=0.4 \mathrm{~m} \text { (Table S7). Data source: Experimental data } 1\end{array}$ \\
\hline & & & $\mathrm{r}=0.4 \mathrm{~m}$ & $\begin{array}{l}\text { Distance from source (BZ; workes are about one armlenght away from the } \\
\text { source). Data source: Workers exposure data[5] }\end{array}$ \\
\hline
\end{tabular}

